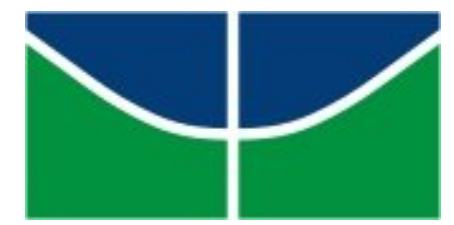

UNIVERSIDADE DE BRASÍLIA

CENTRO DE EXCELÊNCIA EM TURISMO,

ESPECIALIZAÇÃO EM QUALIDADE DE ALIMENTOS

RODRIGO CAVALLARE VIEIRA

VERIFICAÇÃO DE PROCEDIMENTOS DE HIGIENIZAÇÃO DAS MÃOS DE MANIPULADORES DE ALIMENTOS NO VAREJO DO DISTRITO FEDERAL

BRASÍLIA - DF

2009 


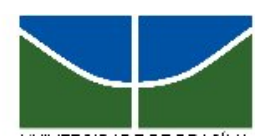

UNIVERSIDADE DE BRASÍLIA

Centro de Excelência em Turismo

Pós-graduação Lato Sensu

Curso de Especialização em Qualidade de Alimentos.

RODRIGO CAVALLARE VIEIRA

VERIFICAÇÃO DE PROCEDIMENTOS DE HIGIENIZAÇÃO DAS MÃOS DE MANIPULADORES DE ALIMENTOS NO VAREJO DO DISTRITO FEDERAL

Monografia apresentada ao Centro de excelência em Turismo - CET, da Universidade de Brasília - UnB, como requisito parcial para obtenção de título de Especialista em Qualidade de Alimentos.

Orientador: MSc. Manoel Silva Neto

BRASÍLIA, MARÇO DE 2009 
VIEIRA, Rodrigo.

Verificação de procedimentos de higienização das mãos de manipuladores de alimentos no varejo do Distrito Federal / Rodrigo Vieira. - Brasília, 2009.

$16 \mathrm{f}$.

Monografia (especialização) - Universidade de Brasília, Centro de Excelência em Turismo, 2009.

Orientador: MSc. Manoel Silva Neto

1. Manipuladores de alimentos. 2. Lavagem de mãos. 3. Testes de verificação. 


\section{VERIFICAÇÃO DE PROCEDIMENTOS DE HIGIENIZAÇÃO DAS MÃOS DE MANIPULADORES DE ALIMENTOS NO VAREJO DO DISTRITO FEDERAL}

Monografia apresentada ao Centro de Excelência em Turismo - CET, da Universidade de Brasília - UnB, como requisito parcial à obtenção do grau de Especialista em Qualidade de Alimentos.

Aprovado em:

MSc. Orientador Manoel Silva Neto

MSc. Luiz Antonio Borgo

MSc. Lucienne Cardoso

Brasília - DF

2009 


\section{DEDICATÓRIA}

Dedico este trabalho ao meu pai Evaldo, que sempre me apoiou em tudo que precisei e sempre fez tudo por minha formação e conhecimento. Obrigado por ser esta pessoa tão presente em minha vida e por me fazer tão feliz. Espero que se orgulhe de mim, pois é por este motivo que trabalho duro; recompensar tudo o que você faz por mim.

Dedico também à minha mãe, Lilian, por ser responsável por eu estar onde estou hoje. Sempre me apoiando e me ajudando em minhas decisões.

À minha namorada, Luana, que está comigo em todas as ocasiões e que é minha raiz, meu porto seguro e ao mesmo tempo é minha imaginação me fazendo perseguir e alcançar meus objetivos, obrigado por me ajudar tanto.

Aos meus avós queridos que já se foram mas que continuam olhando por mim e às minhas avós queridas que estão sempre me dando o carinho que preciso.

A toda minha família e amigos por me darem felicidade e oportunidades de ser uma pessoa melhor a cada dia.

Claro que aos meus mestres e professores que sem eles, eu não seria esta pessoa íntegra e não teria metade dos conhecimentos que tenho hoje. 


\section{AGRADECIMENTOS}

Às Responsáveis Técnicas pelas lojas, Bárbara Lopes e Loiane Mayra e à estagiária de nutrição, Paula Daher, pela colaboração prestada na realização das análises.

À Responsável Técnica Elisa Amaral pelo empréstimo do material para que a revisão de literatura fosse realizada e ao meu orientador e amigo, Manoel Neto, por ter idealizado esta pesquisa e por todo apoio prestado. 
SUMÁRIO

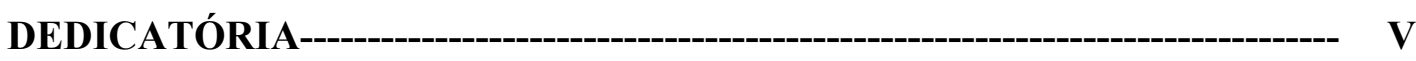

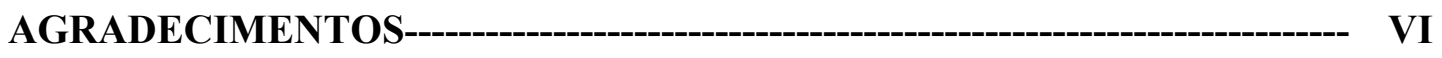

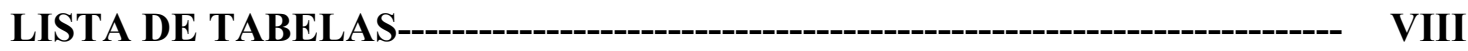

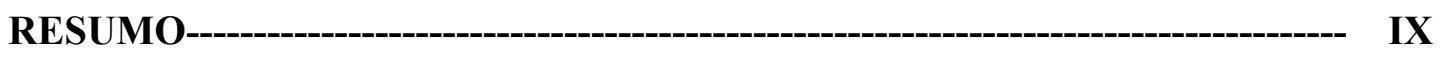

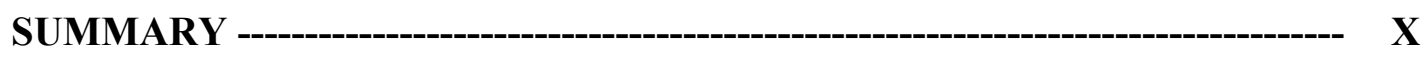

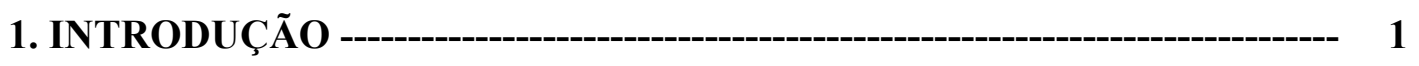

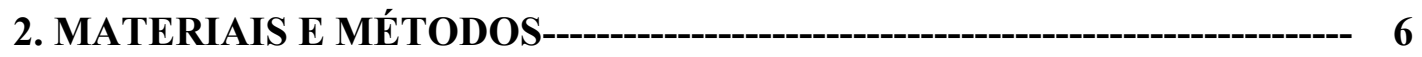

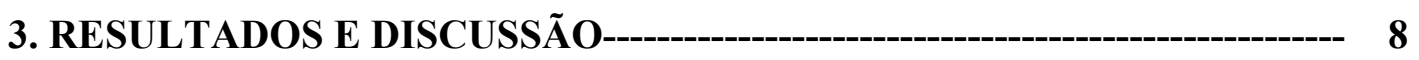

4. CONCLUSÃO--13

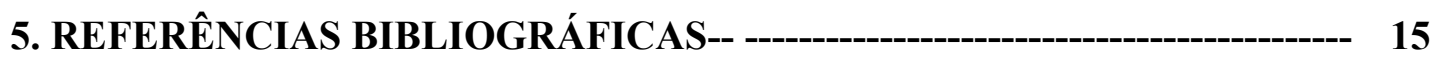

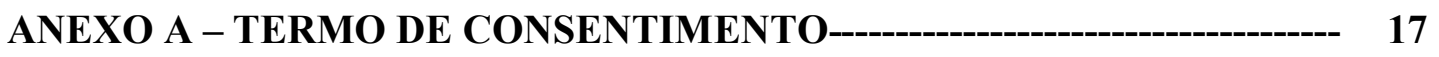




\section{LISTA DE TABELAS}

Tabela 1 - Análises com o teste HY-RiSE® nas mãos dos

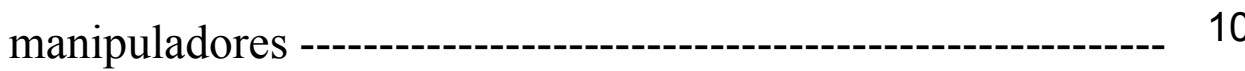

Tabela 2 - Testes para analisar a influência do papel-toalha na coleta de

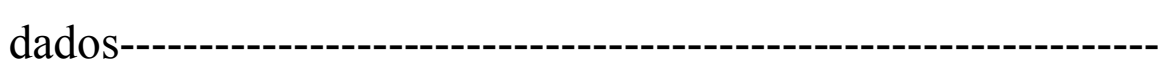

Tabela 3 - Microbiota das mãos pré-lavadas de trabalhadores de indústrias de alimentos e não-alimentos12 


\section{RESUMO}

VIEIRA, Rodrigo. Verificação de Procedimentos de Higienização das mãos de manipuladores de alimentos no varejo do Distrito Federal. 2009. 16p. Monografia Curso de especialização em Qualidade de Alimentos, Centro de Excelência em Turismo UnB. Brasília, 2009.

Orientador: Msc. Manoel Silva Neto. Apresentado em 16/04/2009.

"Nosso principal objetivo não é tentar destruir todos os microorganismos, mas sim evitar que eles sejam ingeridos em grande número.” Essa frase de Guenther Riedel em seu livro, “Controle Sanitário dos Alimentos", demonstra bem o objeto de estudo deste trabalho: testar um método de diagnóstico rápido para garantir que os alimentos não sejam contaminados pelos manipuladores, que apresentam contaminação nas mãos mesmo após a lavagem habitual.

O estudo foi realizado em uma empresa do ramo varejista no Distrito Federal, onde o procedimento de higienização de mãos de 45 manipuladores de 5 lojas foi testado.

Como resultado obteve-se $91 \%$ de contaminação nas mãos higienizadas de manipuladores de alimentos, caracterizando um grande risco à saúde do consumidor.

Textos para indexação: Manipuladores de Alimentos, Lavagem de mãos, Procedimentos de Higienização, Varejo, Testes de verificação e controle, HY-RiSE®. 


\section{SUMMARY}

"Our main purpose isn't try to destroy all microorganisms but avoid consume them a lot." This declaration from Guenther Riedel on his book shows this article's study purpose: Test a fast diagnostic method to guarantee no contamination by the food handler's who shows hands contamination even after the habitual hands washing.

The study was carried out in a market retail company in Distrito Federal. The hands wash procedure was tested with 45 food handlers at 5 different stores. This study identified $92 \%$ of contamination as a result on food handlers hands witch represents a high risk to final consumer.

Index texts: Food handlers, Hand washing, Hygienic procedures, Retail Company, Control and verify tests, HY-RiSE®. 


\section{INTRODUÇÃO}

A microbiologia de alimentos trata tanto dos organismos patogênicos quanto dos deteriorantes. Ela visa conhecer a grande variedade de microorganismos existentes em alimentos. Devido à conscientização do público em relação às doenças transmitidas por alimentos estar aumentando a cada dia, é importante que todas as companhias alimentícias mantenham altos padrões de higiene e garantam a segurança de seus produtos. Obviamente, com o tempo, haverá mudanças tecnológicas na produção e nos métodos de análises microbiológicas. Por este motivo se faz necessário saber os efeitos de mudanças no processamento de um alimento (FORSYTHE, 2002). Com os estabelecimentos de alimentação aumentando em número, observa-se que os alimentos ficaram mais expostos a uma série de perigos ou oportunidades de contaminações microbianas associados a práticas incorretas de manipulação e processamento (ALMEIDA et al., 1995).

Mezomo (1994) entende que higiene dos alimentos não é só a sua manipulação adequada, mas também os cuidados com equipamentos e utensílios utilizados em todo processo de manipulação, tanto dos alimentos crus quanto os processados.

A higienização visa eliminar ou reduzir a contaminação, diminuindo assim a probabilidade de transmissão de agentes causadores de enfermidades. Ela divide-se em duas etapas distintas: a limpeza e a desinfecção. Na limpeza, o objetivo é remoção de resíduos orgânicos e minerais de forma geral. Na desinfecção, o objetivo passa a ser a eliminação de agentes patogênicos e redução de agentes deteriorantes a um nível aceitável - nível de segurança (GERMANO, 2008). Os microrganismos transitórios, representados principalmente pelas bactérias gram-negativas, são facilmente removidos pela lavagem das mãos com bons detergentes. Os microrganismos residentes são de maioria gram-positiva e encontram-se em equilíbrio dinâmico, como parasitas 
ou bactérias saprófitas na pele, embora $10 \%$ a $20 \%$ da microbiota esteja concentrada nas reentrâncias, onde os lipídios e o epitélio dificultam a sua remoção. Em muitas pessoas, os estafilococos tornam-se parte significativa da microbiota residente e, devido à patogenicidade de algumas cepas e capacidade de produzir enterotoxinas, é de grande interesse a sua eliminação nos procedimentos de lavagem das mãos (CRISLEY; FOTER, 1965).

Microorganismos presentes em alimentos crus podem disseminar-se para outros durante a fase de preparação. A contaminação ocorre na maioria das vezes pelas mãos dos manipuladores ou pelos utensílios de cozinha. Assim, tábuas de corte, facas, cortadores, moedores, recipientes e panos de limpeza constituem veículos comuns para transmissão de agentes (FORSYTHE, 2002).

Para que um manipulador contamine um alimento, são necessários alguns passos: que sejam excretados microorganismos em quantidade suficiente (fezes, supurações de ouvido, nariz, garganta, bocas, olhos e pele); que os microorganismos passem para as mãos ou partes expostas do corpo e que entrem em contato direto com o alimento; que os microorganismos sobrevivam o suficiente para contaminar o alimento; que o alimento não seja submetido a tratamento capaz de destruir os microorganismos; que o número de microorganismos constitua a dose infectante (GERMANO, 2008).

O Center for Disease Control-CDC, relatou dados relativos a surtos de toxinfecções alimentares nesses estabelecimentos nos EUA, que apontam o manipulador de alimentos como responsável por $26 \%$ desses surtos (SILVA JR. et al., 1990).

Os manipuladores de alimentos raramente possuem um conhecimento extenso e aprofundado sobre higiene de alimentos, por isso torna-se altamente recomendado a apresentação de cursos práticos de treinamentos (RIEDEL, 2005).

Os problemas de toxinfecções alimentares associadas aos manipuladores, são reconhecidos por muitas comunidades com melhor estrutura social do que a do Brasil, como é o caso da Europa, 
EUA e em especial do Canadá, onde desde $1^{\circ}$ de julho de 2000, na província da Britsh Columbia, foi criada uma regulamentação exigindo que os manipuladores, antes de trabalhar com serviços de alimentação de qualquer espécie, devem fazer um curso de alimento seguro. Cada estabelecimento deve ter no mínimo um manipulador por turno que fez o curso (CANADÁ, 2002).

$\mathrm{Na}$ maioria das produções de alimentos e operações de manipulação de alimentos, os manipuladores recebem pouco ou nenhum treinamento sobre lavagem de mãos. As autoridades regulatórias ou órgãos fiscalizadores apenas checam se existe uma pia exclusiva para lavagem das mãos na área de preparo com desligamento não-manual, se está abastecida com detergente para a lavagem de mãos e se esta pia funciona perfeitamente. Verificar apenas a estrutura para lavagem de mãos significa não verificar se esses manipuladores estão lavando as mãos suficientemente para reduzir a contaminação de patógenos a níveis seguros (SNYDER, 1988). A incidência de doenças relacionadas à alimentação demonstra que estabelecimentos de produção de alimentos precisam ter um sério controle do processo de produção. (BRASIL apud ROSSI, 2006).

A produção de alimentos seguros requer controle na fonte; controle do desenvolvimento e do processo dos produtos; boas práticas higiênicas durante a produção, processamento, manipulação, distribuição, estocagem, venda, preparação e utilização; e a abordagem deve ser preventiva, uma vez que a efetividade dos testes microbiológicos de produtos finais é limitada.

Por esta razão, analisar amostras alimentícias e ambientais quanto à presença de microorganismos e toxinas, é uma prática padrão para garantir a segurança e qualidade do alimento. Porém a interpretação destes resultados é muito mais difícil do que é normalmente apresentado. 
Os procedimentos convencionais são trabalhosos e consomem muito tempo. Portanto, métodos rápidos têm sido desenvolvidos para encurtar o tempo entre cada coleta da amostra e obtenção do resultado (FORSYTHE, 2002).

A detecção e rápida correção das falhas no processamento dos alimentos, bem como a adoção de medidas preventivas, são hoje a principal estratégia para o controle de qualidade desses produtos para a sobrevivência dessas empresas (ALMEIDA et al., 1995).

Todos os setores de produção enfrentam o desafio da qualidade de seus produtos. Em particular; na indústria de alimentos, os procedimentos de higienização são fundamentais para assegurar a qualidade (GERMANO, 2008).

Tradicionalmente, as medidas de controle incluem a implementação de técnicas de lavagem das mãos, treinamento e conscientização dos profissionais envolvidos no preparo, armazenamento e distribuição de alimentos (BRODYE, 1965).

É difícil rastrear o alimento responsável por um surto ou uma toxinfecção ocorrida, pois o consumidor dificilmente informa quais alimentos poderiam estar inadequados nas suas últimas refeições e devido aos microorganismos possuírem um período de incubação muito variado, sendo mais fácil e mais barato um controle prévio a um controle da enfermidade em si. (FORSYTHE, 2002; SNYNER, 1988).

Segundo Akutsu et al. (1995), o nível educacional dos manipuladores de alimentos no Brasil é relativamente baixo comparado a esses países; por isso, planejou-se a realização deste estudo com o objetivo de verificar procedimentos de higienização das mãos de manipuladores de estabelecimentos no Distrito Federal, além de verificar testes rápidos dentro da rotina dos procedimentos operacionais, caracterizar a situação atual em relação ao conhecimento, medir o nível de treinamento dos manipuladores e diferenciar a carga de matéria orgânica de uma lavagem de mãos correta e a realizada pelos manipuladores. 
Com este trabalho espera-se demonstrar as condições higiênico-sanitárias das mãos dos manipuladores após a lavagem e diferenciá-las de uma lavagem correta que será o grupo controle. 


\section{MATERIAIS E MÉTODOS}

O estudo em questão é uma pesquisa transversal exploratória, tendo como objetivo determinar se existe contaminação nas mãos de manipuladores de estabelecimentos varejistas no Distrito Federal.

A população do presente estudo é de uma empresa do ramo varejista escolhida por conveniência. A pesquisa foi realizada junto a uma amostragem de cinco lojas que trabalham com manipulação de alimentos no Distrito Federal, utilizando testes rápidos do kit HY-RiSE® (50 testes rápidos). O kit de teste HY-RiSE® fornece um método de limpeza geral de superfícies de equipamentos, utensílios, mãos e água de enxágues de sistemas C.I.P. (Cleaning In Place), detectando contaminações orgânicas sob a forma de resíduos dos produtos que permanecem após uma limpeza insuficiente.

A amostragem foi realizada por conveniência, ou seja, serão realizados testes com dez manipuladores de cada loja, escolhidos por sorteio eletrônico usando o programa EXCEL. Entre os dez manipuladores outro sorteio eletrônico foi realizado da mesma maneira onde ocorreu a escolha de 1 (um) manipulador para o grupo controle. O colaborador do grupo controle foi orientado durante a lavagem das mãos.

No final do estudo, realizou-se 50 testes rápidos sendo 45 de manipuladores sem a orientação técnica e 5 do grupo controle.

Os colaboradores que não têm relação com manipulação de produtos perecíveis foram previamente excluídos desta pesquisa, pois não representam risco significativo para a saúde do consumidor. 
A coleta dos dados foi realizada no mês de março de 2009 nas lojas participantes em horário comercial, onde foi solicitado ao manipulador que lavasse as mãos. Após esse procedimento, realizou-se um teste rápido (HY-RiSE®) que detecta a quantidade de matéria orgânica (NAD, NADH, NADPH) presente na mão do manipulador e anotaram-se os resultados em uma planilha contendo especificações da loja, do manipulador em questão e a data da coleta.

Para a pesquisa, utilizou-se detergente anti-séptico próprio para lavagem das mãos fabricado por uma empresa multinacional, reconhecida no mercado como idônea e devidamente registrada no Ministério da Saúde.

Como o grupo controle teve um resultado fora do esperado, e o kit do teste HY-RiSE® vem com algumas lâminas e quantidade de reagentes a mais que as 50, decidiu-se mensurar a interferência do papel-toalha utilizado para a secagem das mãos, realizando 3 testes $(1,2$ e 3$), 2$ sem a parte de secagem das mãos com papel-toalha (1 e 2) e 1 com a secagem normal das mãos (3).

Por questões éticas, os nomes dos colaboradores, da empresa e das lojas participantes não serão mencionados. Para sua identificação serão dadas as seguintes denominações: Manipuladores M (M1, M2, M3,.....M45), Controle C (C1, C2, C3, C4, C5), a empresa $\left(\mathrm{R}_{1}\right)$, as Seções S (S1, S2, $\mathrm{S} 3, \mathrm{~S} 4, \mathrm{~S} 5)$ e Lojas $\left(\mathrm{R}_{1} 1482, \mathrm{R}_{1} 2093, \mathrm{R}_{1} 4827, \mathrm{R}_{1} 8535, \mathrm{R}_{1} 7456\right)$.

O responsável pela coleta de amostras utilizou-se da higiene em todos os processos de coletas realizando lavagem das mãos e utilizando luvas para diminuir o risco de obtenção de resultados falsos ou comprometidos. As luvas eram trocadas a cada nova coleta.

A compilação dos dados das planilhas foi realizada após finalização de todos os testes.

Como se trata de dados com variáveis simples, de duas opções, de contaminação presente ou não presente, foi realizada uma análise quantitativa simples com cálculos estatísticos descritivos usando o Excel como instrumento. 


\section{RESULTADOS E DISCUSSÃO}

Um interessante estudo nos Estados Unidos demonstrou que 24,8\% das ocorrências de surtos de toxinfecção são originadas por manipuladores portadores de micróbios (RIEDEL, 2005).

Em um estudo de Almeida et al. (1995), foi observado que os manipuladores avaliados raramente lavavam as mãos quando entravam na cozinha ou durante a preparação dos alimentos. Desta forma, verifica-se a necessidade de introduzir métodos adequados de higienização para as mãos, com a finalidade de prevenir a transmissão de microrganismos patogênicos para os alimentos.

Os resultados do presente estudo mostram que $91 \%$ dos manipuladores tiveram resultado positivo para contaminação, não importando o seu grau. Ou seja, dos 45 manipuladores testados, 41 apresentaram contaminações em graus distintos conforme pode ser visualizado na tabela 1.

Como em nenhum momento houve interferência na lavagem das mãos ou nas atitudes tomadas após esse procedimento, houve muitas diferenças nos graus de contaminação e de atitudes dos manipuladores. Ocorreu, por exemplo, casos de colaboradores que, após a lavagem das mãos, as secaram em seus aventais; outros, além de lavar as mãos apenas com água, usaram o papel toalha para secar o rosto e ainda arrumavam o contentor de cabelos antes do teste. Desta forma pôde-se perceber que dependendo da lavagem realizada, o nível de contaminação apresentada variava de acordo. Ou seja, quanto pior a técnica de higienização, maior o nível de contaminação.

O grupo controle teve um resultado fora do esperado, com $80 \%$ dos manipuladores contaminados. De 5 manipuladores controle, apenas 1 não apresentou contaminação. Apesar do detergente utilizado ser registrado no Ministério da Saúde e ser de uma empresa idônea e conhecida no mercado mundial, não se sabe se havia ou não contaminação e nem a sua eficácia real do produto. 
O resultado do teste de lavagem de mãos sem a secagem com papel toalha apresentou contaminações em $100 \%$ e em grau maior que alguns colaboradores conforme pode ser visualizado na tabela 2. A explicação para este resultado pode ser a não retirada completa do detergente apenas com a ação da água.

Quando se efetuou o último teste com a secagem de mãos normal, o resultado deu negativo para contaminações, demonstrando que com a técnica correta de lavagem e secagem das mãos os resultados tendem à conformidade. (tabela 2).

O resultado desse estudo é próximo ao do estudo de Souza et. al. (2007), as mãos dos manipuladores contêm em sua microbiota natural Staphylococcus aureus em 85,7\% dos testes realizados, sendo eles o elo principal para o estudo epidemiológico da contaminação estafilocócica.

Em estudo similar, Rossi (2006), realizou análises das mãos de manipuladores de alimentos de restaurantes em Belo Horizonte - MG que demonstraram contaminação por Staphylococcus spp e Salmonella spp em $84,6 \%$ e $30,8 \%$, respectivamente. Naquelas amostras, foi observada também a possibilidade de contaminação por $E$. coli em $26,9 \%$, mesmo após a higienização habitual.

A tabela 3 demonstra bem o nível de contaminação das mãos dos manipuladores de alimentos de cada tipo de indústria (deWIT, 1984). 
Tabela 1 - Análises com o teste HY-RiSE® nas mãos dos manipuladores.

\begin{tabular}{|c|c|c|c|c|c|c|}
\hline \multicolumn{7}{|c|}{ EMPRESA R1 } \\
\hline Data & Hora & Loja & Seção & Amostras & Conforme & $\begin{array}{c}\text { Não } \\
\text { conforme }\end{array}$ \\
\hline $19 / 3 / 2009$ & 09:09 & $\mathrm{R}_{1} 4827$ & S4 & M1 & $\sqrt{ }$ & \\
\hline $19 / 3 / 2009$ & 09:10 & $\mathrm{R}_{1} 4827$ & $\mathrm{~S} 4$ & M2 & & $x$ \\
\hline $19 / 3 / 2009$ & $09: 27$ & $\mathrm{R}_{1} 4827$ & $\mathrm{~S} 1$ & M3 & & $x$ \\
\hline $19 / 3 / 2009$ & 09:36 & $\mathrm{R}_{1} 4827$ & $\mathrm{~S} 1$ & M4 & & $x$ \\
\hline $19 / 3 / 2009$ & $09: 46$ & $\mathrm{R}_{1} 4827$ & S5 & M5 & & $x$ \\
\hline $19 / 3 / 2009$ & $09: 54$ & $\mathrm{R}_{1} 4827$ & S5 & M6 & $\sqrt{ }$ & \\
\hline $19 / 3 / 2009$ & $10: 06$ & $\mathrm{R}_{1} 4827$ & S3 & M7 & & $x$ \\
\hline $19 / 3 / 2009$ & $10: 28$ & $\mathrm{R}_{1} 4827$ & S3 & M8 & & $x$ \\
\hline 19/3/2009 & $10: 40$ & $\mathrm{R}_{1} 4827$ & S2 & M9 & $\sqrt{ }$ & \\
\hline $19 / 3 / 2009$ & $10: 43$ & $\mathrm{R}_{1} 4827$ & $\mathrm{~S} 2$ & $\mathrm{C} 1$ & & $x$ \\
\hline $19 / 3 / 2009$ & $11: 31$ & $\mathrm{R}_{1} 8535$ & $\mathrm{~S} 1$ & M10 & & $x$ \\
\hline $19 / 3 / 2009$ & $11: 34$ & $\mathrm{R}_{1} 8535$ & $\mathrm{~S} 1$ & M11 & & $\times$ \\
\hline $19 / 3 / 2009$ & $11: 45$ & $\mathrm{R}_{1} 8535$ & S5 & M12 & & $x$ \\
\hline $19 / 3 / 2009$ & $11: 48$ & $R_{1} 8535$ & S5 & M13 & & $x$ \\
\hline $19 / 3 / 2009$ & $12: 00$ & $\mathrm{R}_{1} 8535$ & $\mathrm{~S} 2$ & $\mathrm{C} 2$ & $\sqrt{ }$ & \\
\hline $19 / 3 / 2009$ & $12: 03$ & $\mathrm{R}_{1} 8535$ & S2 & M14 & & $x$ \\
\hline 19/3/2009 & $12: 15$ & $R_{1} 8535$ & S3 & M15 & & $x$ \\
\hline $19 / 3 / 2009$ & $12: 26$ & $R_{1} 8535$ & S3 & M16 & & $x$ \\
\hline $19 / 3 / 2009$ & $12: 31$ & $\mathrm{R}_{1} 8535$ & S4 & M17 & & $x$ \\
\hline 19/3/2009 & $12: 33$ & $R_{1} 8535$ & S4 & M18 & & $x$ \\
\hline $19 / 3 / 2009$ & $14: 01$ & $\mathrm{R}_{1} 7456$ & S3 & M19 & & $x$ \\
\hline $19 / 3 / 2009$ & $14: 04$ & $\mathrm{R}_{1} 7456$ & S5 & M20 & & $x$ \\
\hline $19 / 3 / 2009$ & $14: 15$ & $\mathrm{R}_{1} 7456$ & S5 & C3 & & $x$ \\
\hline $19 / 3 / 2009$ & $14: 23$ & $\mathrm{R}_{1} 7456$ & S5 & M21 & & $x$ \\
\hline $19 / 3 / 2009$ & $14: 35$ & $\mathrm{R}_{1} 7456$ & $\mathrm{~S} 2$ & M22 & & $x$ \\
\hline 19/3/2009 & $14: 48$ & $\mathrm{R}_{1} 7456$ & S1 & M23 & & $x$ \\
\hline $19 / 3 / 2009$ & $14: 52$ & $R_{1} 7456$ & $\mathrm{~S} 1$ & M24 & & $x$ \\
\hline $19 / 3 / 2009$ & $15: 03$ & $\mathrm{R}_{1} 7456$ & S3 & M25 & & $x$ \\
\hline $19 / 3 / 2009$ & $15: 18$ & $\mathrm{R}_{1} 7456$ & S4 & M26 & & $x$ \\
\hline $19 / 3 / 2009$ & $15: 24$ & $\mathrm{R}_{1} 7456$ & S4 & M27 & & $x$ \\
\hline
\end{tabular}


Tabela 1 - Análises com o teste HY-RiSE® nas mãos dos manipuladores (continuação).

\begin{tabular}{cccccc}
\hline $20 / 3 / 2009$ & $13: 40$ & $R_{1} 1482$ & $S 2$ & $M 28$ & $\times$ \\
$20 / 3 / 2009$ & $13: 55$ & $R_{1} 1482$ & $S 5$ & $M 29$ & $\times$ \\
$20 / 3 / 2009$ & $14: 00$ & $R_{1} 1482$ & $S 5$ & $M 30$ & $\times$ \\
$20 / 3 / 2009$ & $14: 12$ & $R_{1} 1482$ & $S 1$ & $M 31$ & $\times$ \\
$20 / 3 / 2009$ & $14: 30$ & $R_{1} 1482$ & $S 5$ & $M 32$ & $\times$ \\
$20 / 3 / 2009$ & $14: 48$ & $R_{1} 1482$ & $S 4$ & $M 33$ & $\times$ \\
$20 / 3 / 2009$ & $14: 51$ & $R_{1} 1482$ & $S 4$ & $M 34$ & $\times$ \\
$20 / 3 / 2009$ & $15: 00$ & $R_{1} 1482$ & $S 1$ & $M 35$ & $\times$ \\
$20 / 3 / 2009$ & $15: 05$ & $R_{1} 1482$ & $S 3$ & $M 36$ & $\times$ \\
$20 / 3 / 2009$ & $15: 08$ & $R_{1} 1482$ & $S 3$ & $C 4$ & $\times$ \\
$20 / 3 / 2009$ & $16: 18$ & $R_{1} 2093$ & $S 5$ & $M 37$ & $\times$ \\
$20 / 3 / 2009$ & $16: 21$ & $R_{1} 2093$ & $S 5$ & $M 38$ & $\times$ \\
$20 / 3 / 2009$ & $16: 36$ & $R_{1} 2093$ & $S 3$ & $M 39$ & $\times$ \\
$20 / 3 / 2009$ & $16: 38$ & $R_{1} 2093$ & $S 3$ & $M 40$ & $\times$ \\
$20 / 3 / 2009$ & $16: 51$ & $R_{1} 2093$ & $S 2$ & $M 41$ & $\times$ \\
$20 / 3 / 2009$ & $17: 08$ & $R_{1} 2093$ & $S 1$ & $M 42$ & $\times$ \\
$20 / 3 / 2009$ & $17: 10$ & $R_{1} 2093$ & $S 1$ & $M 43$ & $\times$ \\
$20 / 3 / 2009$ & $17: 22$ & $R_{1} 2093$ & $S 4$ & $M 44$ & $\times$ \\
$20 / 3 / 2009$ & $17: 28$ & $R_{1} 2093$ & $S 4$ & $M 45$ & $\times$ \\
$20 / 3 / 2009$ & $17: 47$ & $R_{1} 2093$ & $S 2$ & $C 5$ & \\
\hline & & & & & $\times$
\end{tabular}


Tabela 2 - Testes para analisar a influência do papel-toalha na coleta de dados.

\begin{tabular}{cccccccc}
\hline \multicolumn{7}{c}{ Testes complementares } \\
\hline Data & Hora & Loja & Seção & Amostras & Conforme & Não conforme & Comentários \\
\hline $21 / 3 / 2009$ & $09: 20$ & - & - & 1 & $\times$ & Sem secagem \\
$21 / 3 / 2009$ & $09: 30$ & - & - & 2 & & das mãos \\
& & & & & & & Sem secagem \\
$21 / 3 / 2009$ & $09: 47$ & - & - & 3 & $\sqrt{ }$ & das mãos \\
\hline
\end{tabular}

Tabela 3 - Microbiota das mãos pré-lavadas de trabalhadores de indústrias de alimentos e não-alimentos

\begin{tabular}{lcccccc}
\hline & & \multicolumn{3}{c}{} & \multicolumn{3}{c}{ \% das mãos com: } \\
Indústria de alimentos & N. pessoas & $\begin{array}{c}\text { N. Total de } \\
\text { Bactérias } \\
(\mathbf{l o g} 10)\end{array}$ & $\begin{array}{c}\text { Enterobacteriaceae } \\
\text { (log 10) }\end{array}$ & Salmonella & E. coli & S. aureus \\
\hline Abatedouro de Aves & 14 & 6.20 & 3.53 & 36 & 86 & 100 \\
Abatedouro Bovino & 20 & 7.30 & 3.90 & 5 & 100 & 65 \\
Abatedouro Suíno & 20 & 6.78 & 3.38 & 30 & 95 & 95 \\
Produtos de ovos I & 20 & 6.28 & 3.59 & 25 & 60 & 55 \\
Produtos de ovos II & 20 & 5.81 & 2.08 & 0 & 30 & 70 \\
Peixes & 19 & 6.28 & 2.62 & 0 & 15 & 45 \\
Laticínios & 26 & 5.81 & 1.98 & 0 & 19 & 54 \\
Comidas congeladas & 18 & 6.28 & 2.49 & 0 & 50 & 50 \\
Vegetais desidratados & 14 & 5.97 & 2.34 & 0 & 7 & 29 \\
Fábrica de biscoitos & 28 & 6.26 & 2.34 & 0 & 11 & 46 \\
Fábrica de chocolate & 28 & 5.63 & 1.76 & 0 & 4 & 29 \\
\hline Indústria não-alimentos & & & & & & \\
\hline Fábrica de algodão & 15 & 5.31 & 2.06 & 0 & 80 & 53 \\
Fábrica de vidros & 14 & 5.95 & 1.74 & 0 & 0 & 64 \\
Fábrica de latas & 15 & 5.68 & 1.14 & 0 & 60 \\
\hline
\end{tabular}

Fonte: Adaptado de deWit, J. C. 1984. 


\section{CONCLUSÕES}

Os resultados obtidos nos testes rápidos demonstraram a grande capacidade de sobrevivência dos microorganismos e a grande deficiência que os manipuladores têm na higienização das mãos.

É correto afirmar que houve muitas diferenças de graus de contaminação e de atitudes dos manipuladores.

Pelo resultado inesperado do grupo controle, sugere-se um novo estudo para averiguar a capacidade de higienização do detergente, comparação com o mesmo produto de outra empresa e até mesmo a comparação do detergente com outros produtos de diferentes composições químicas.

A hipótese do papel-toalha foi parcialmente descartada uma vez que algumas das seções possuíam apenas papel-toalha reciclado para a secagem das mãos. Desta forma, Sugere-se também um novo estudo para analisar a capacidade de contaminação do papel reciclado.

O teste HY-RiSE® atuou como uma arma poderosa de controle e conscientização do problema contaminação nas áreas de manipulação.

Trata-se de um teste multifuncional, pois pode ser utilizado para verificação de higienização de mãos, superfícies, equipamentos, utensílios e até atesta a qualidade de água. É certo que não se trata de um método descritivo, onde podemos analisar que microorganismo está presente e que tipo de riscos se corre, mas a vantagem é a rapidez e o impacto causado pelo resultado do teste no manipulador. O que o torna facilmente adaptável para a rotina operacional. 
De fato, seria ótimo que pudéssemos contar com um teste rápido como este em locais de manipulação de alimentos, pois funcionaria como um procedimento operacional padrão (POP), onde seriam gerados gráficos e planilhas, mantendo um controle rigoroso sobre a higienização de equipamentos e utensílios, bem como sobre a higienização periódica das mãos, mantendo uma carga microbiana baixa, garantindo assim, um baixo risco de contaminação dos alimentos.

Uma pesquisa complementar a esta pode ser realizada em equipamentos e utensílios gerando, assim, uma "fotografia" por completo da situação que se encontra a rede varejista em termos de higienização. 


\section{REFERÊNCIAS BIBLIOGRÁFICAS}

\section{ABERCEM NOTÍCIAS: Boletim Informativo da Associação Brasileira de Empresas de Refeições Coletivas. São Paulo, 1990.}

2. ALMEIDA R. de C. C.; KUAYE A. Y.; SERRANO A. de M.; ALMEIDA P. F., Avaliação e controle da qualidade microbiológica de mãos de manipuladores de alimentos. Rev. Saúde Pública, 29 (4) 290-94. 1995.

3. AKutsu, R. de C.; BOtelho, R. A.; CAMARgo, E. B.; SÁViO, K. E. O.; ARAÚJO, W. C. Adequação de Boas Práticas de Fabricação em Serviços de Alimentação. Revista de Nutrição. v. 18, n. 3. p. 419-427, 2005

3. BRASIL. Portaria ${ }^{\circ} 368$ de 4 de setembro de 1997 . Regulamento técnico sobre as condições higiênico-sanitárias e de boas práticas de elaboração para estabelecimentos elaboradores ou industrializadores de alimentos. Disponível em <www.agricultura.gov.br>. Acesso em: 13 dezembro 2008.

4. BRODYE, J. Hand hygiene. Scot. Med. J., 10: 115-25, 1965.

5. CANADÁ. Foodsafe workbook. 3 ed. Victoria, British Columbia - CA. Centre for Curriculum, Transfer \& Technology. Ministry of Advanced Education Province of British Columbia. 2002, pg. VI, VII.

6. CRISLEY, F. D. \& FOTER, M. J. The use of antimicrobial soaps and detergents for hand washing in foodservice establishments. J. Milk Food Technol., 28: 278-84, 1965.

7. FORSYTHE, S. J. - Microbiologia da segurança alimentar. Porto Alegre, RS; Artmed, 2002. p, V e VI; 13; 205-211; 79.

8. GERMANO, P. M. L. Higiene e Vigilância Sanitária de Alimentos, 3 ed., Barueri, SP; Manole, 2008, pg. 600-605; 79,80.

9. MEZOMO, F. B. I. Administração de Serviço de Alimentação, 4 ed, São Paulo, Mezomo, 1994, p. 162 
10. RIEDEL, G. Controle Sanitário dos Alimentos. 3 ed., São Paulo, SP; Atheneu, 2005, pg. 405-410.

11. ROSSI, C. F. Condições Higiênico-Sanitárias de Restaurantes Comerciais do Tipo Self-Service de Belo Horizonte - MG. 2006. 142f. Dissertação (Pós-Graduação em Ciência dos Alimentos) - Faculdade de Farmácia da Universidade Federal de Minas Gerais, Belo Horizonte, MG, 2006.

12. SILVA Jr., E. A.; IARIA, S. T.; ANDRADE, C. R.; MARTINS, E. A. Fundamentos para diagnóstico e prevenção das toxinfecções alimentares na cozinha industrial. São Paulo, 1990.

13. SNYDER, O. P. Safe Hand Washing. St. Paul, MN, Hospitality Institute of Technology and Management, 1988.

14. SOUZA, J. G.; COSTA, F.N.; ALVES, L.M.C.; MACHADO, P.P.; LEITE, P.R. S.C. Pesquisa de estafilococos coagulase positiva em manipuladores de uma unidade de alimentação, na cidade de São Luís, MA. Revista Higiene Alimentar, Vol. 21, n. 152, junho 2007.

15. deWIT, J. C. and E. H. KAMPELMACHER. Some aspects of bacterial contamination of hands of workers in foodservice establishments. J. Bacteriol. Hyg. 186(1): 9-12, 1984. 
ANEXOS

ANEXO A - Termo de Consentimento 


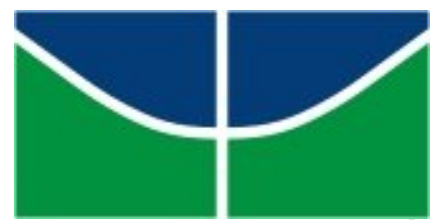 \\ UNIVERSIDADE DE BRASÍLIA \\ CENTRO DE EXCELENCIA EM TURISMO, ESPECIALIZAÇÃO EM QUALIDADE DE ALIMENTOS}

PROJETO Verificação de procedimentos de higienização

Pesquisadores responsáveis:

Rodrigo Cavallare Vieira

MSc. Manoel da Silva Neto

\section{TERMO DE CONSENTIMENTO}

Recebi orientação e declaro estar ciente dos objetivos desta pesquisa, que visa, principalmente, verificar $\circ$ procedimento de higienização das mãos dos manipuladores de alimentos. Dessa forma, aceito participar de livre e espontânea vontade da mesma, no que diz respeito à solicitação de higienização das mãos, bem como a utilização do teste rápido em minhas mãos e que o mesmo não causará nenhum dano à minha saúde.

FUI INFORMADO(A) DE QUE OS DADOS TERÃO GARANTIA DE SIGILO POR PARTE DOS PESQUISADORES.

Brasília, de de 